\title{
Clinical significance of upper airway dysfunction in motor neurone disease
}

\author{
Eduardo García-Pachón, Joan Martí, Mercè Mayos, Pere Casan, Joaquín Sanchis
}

\begin{abstract}
Background - To assess the occurrence, functional characteristics and prognostic value of upper airway dysfunction in motor neurone disease, 27 patients unselected for respiratory symptoms were studied.

Methods - Upper airway function was evaluated by analysis of the maximal flow-volume loop. Neurological diagnosis was established from the clinical history and physical examination. The degree of impairment was quantified by the Appel score.

Results - Twelve patients (group A) showed abnormalities of the maximal flow-volume loop consistent with flow limitation (seven patients) or instability of upper airway function (gross oscillations of airflow, five patients). The remaining 15 patients (group B) exhibited a normal or generally reduced maximal flow-volume loop, suggestive of muscle weakness. No differences were observed between groups in general physical condition, rate of disease progression, or duration of disease. Conclusions - Upper airway dysfunction in patients with motor neurone disease was a frequent finding. It was present more often, but not exclusively, in patients with bulbar features and was unrelated to prognosis.
\end{abstract}

(Thorax 1994;49:896-900)

Motor neurone disease comprises a group of clinical conditions caused by progressive degeneration of upper and/or lower motor neurones. The most frequent form of motor neurone disease in adults is amyotrophic lateral sclerosis, a term used to describe the clinical syndrome of combined upper and lower motor neurone signs in the bulbar and/or the spinal region.

Respiratory symptoms in patients with motor neurone disease usually appear late and the monitoring of respiratory function by simple spirometry has been reported to be the best prognostic indicator in these patients. ${ }^{1}$ Neuromuscular diseases such as motor neurone disease, especially with bulbar manifestations, can give rise to upper airway dysfunction. ${ }^{2}$ Bulbar involvement may lead to abnormalities of the control and strength of the laryngeal and pharyngeal muscles. This can affect indices measured from the flow-volume loop which are usually taken to signify upper airway obstruction. ${ }^{34}$ In addition there may be considerable oscillations of flow in the loop. ${ }^{5}$ As- sociated weakness of the respiratory muscles may also contribute to and compound these abnormalities.

In patients with motor neurone disease bulbar involvement is usually associated with a poorer prognosis, ${ }^{6}$ mainly due to aspiration pneumonia. We reasoned that, if dysfunction of the upper airway is related to bulbar involvement, its evaluation at presentation might be of clinical relevance to patients with motor neurone disease.

We aimed to establish the presence and characteristics of upper airway dysfunction in patients with motor neurone disease at the time of diagnosis and to assess its relation with bulbar abnormalities and prognosis.

\section{Methods}

\section{PATIENT CHARACTERISTICS}

Thirty consecutive patients with a clinical diagnosis of motor neurone disease were referred to the pulmonary laboratory from the neurology outpatient clinic of our hospital between September 1987 and January 1991. All had their pulmonary function evaluated at the time of the initial referral and were not selected for respiratory symptoms. Neurological diagnosis was established from the clinical history, physical examination, neurophysiological studies, and disease progression. Bulbar involvement was defined by the presence of dysarthria or dysphagia, or both. Involuntary crying or laughter were considered manifestations of associated pseudobulbar palsy. Compressive lesions of the brain or spine were excluded in all cases by magnetic resonance imaging.

Twenty two patients had amyotrophic lateral sclerosis, three had progressive muscular atrophy, one progressive bulbar palsy, and one primary lateral sclerosis. Three other patients were excluded from the study, one because of concomitant severe pulmonary disease and two because of their inability to perform the tests at the first visit. The mean (SD) age of the 27 patients (14 women, 13 men) was 58 (12) years.

MEASUREMENTS OF PULMONARY FUNCTION Maximal flow-volume loop and maximal voluntary ventilation $\left(M V_{15}\right)$ measurements were performed according to standard recommendations ${ }^{7}$ using a pneumotachograph attached to a microprocessor (Datospir 92, Sibelmed, Barcelona, Spain). Static lung volumes were measured by the helium dilution method (PFL 2450, Sensormedics, Holland). Maximal static respiratory pressures (Pmax) 
were obtained by the Black and Hyatt technique $^{8}$ using a solid state pressure transducer (Sibelmed Model 163, Barcelona, Spain). Reference values for the maximal flow-volume loop were those of Roca $e t a l,{ }^{9}$ for lung volumes and MVV were those of Cotes, ${ }^{10}$ and for Pmax those of Black and Hyatt. ${ }^{8}$

Variable degrees of muscle weakness can either mimic airflow obstruction or make an obstruction less apparent in the maximal flowvolume loop. For this reason we refer to "flow limitation" whenever suggested by the shape and indices of the maximal flow-volume loop with the term "limitation", although it would not necessarily imply an anatomical impediment. Upper airway function was assessed from the shape of the maximal flow-volume loop, and the presence of flow limitation ${ }^{11}$ or gross flow oscillations ${ }^{512}$ was recorded. Upper airway flow limitation was defined by the presence of at least two of the following features: the ratio of forced expiratory volume in one second to the peak expiratory flow $\left(F E V_{1} / P E F\right)$ $>10 \mathrm{ml} / \mathrm{l} / \mathrm{min},{ }^{313}$ the ratio of $\mathrm{FEV}_{1}$ to forced expiratory volume in 0.5 seconds $\left(\mathrm{FEV}_{1} /\right.$ $\left.\mathrm{FEV}_{0.5}\right)>1 \cdot 5,^{3}$ the ratio of maximum mid expiratory flow to maximum mid inspiratory flow $\left(\mathrm{FEF}_{50} / \mathrm{FIF}_{50}\right)>1,{ }^{314}$ the ratio of $\mathrm{MVV}_{15}$ to $\mathrm{FEV}_{1}<25,{ }^{415}$ and $\mathrm{FIF}_{50}<1001 / \mathrm{min}^{3}$ Flow oscillations were defined as a reproducible sequence of at least three gross accelerations and decelerations of flow. ${ }^{5}$ When present, flow oscillations precluded a precise evaluation of the aforementioned indices of flow limitation. In patients in whom the maximal flow-volume loop was classified as being suggestive of upper airway instability the presence of obstruction was therefore not excluded.

DEGREE OF IMPAIRMENT AND DISEASE PROGRESS The degree of bulbar involvement and general impairment was evaluated by the Appel score ${ }^{16}$ which gives a quantitative asssessment of muscle power related to involvement of bulbar and spinal lower motor neurones and measurement of forced vital capacity (FVC) such that the greater the impairment the higher the score (minimum 30 points, maximum 164). The bulbar score was derived from evaluation of swallowing and speech, each of which was ranked according to five degrees of severity ranging from 6 points for normal functioning to 30 points for the most severe abnormality of either function. The relevant clinical information, Appel score, and pulmonary function were recorded for all patients at the first visit and for 21 patients at each subsequent visit until death or the end of the period of observation. In the present study the progress of the disease was assessed by the "rate of progression", which refers to average monthly variation in Appel score in a given patient. The rate of progression was calculated by dividing the difference between present and previous Appel scores by the number of days elapsed between the two evaluations, and then multiplying the result by 30 (days in a month).

\section{STATISTICAL ANALYSIS}

Comparison of mean data was carried out with the Mann-Whitney test and correlations were compared by the Spearman's test. Statistical significance was accepted at $\mathrm{p}<0 \cdot 05$.

\section{Results}

LUNG FUNCTION TESTS

The pulmonary function data of the patients at their first visit are shown in table 1 . Overall the patients initially showed a small reduction in $\mathrm{FEV}_{1}$ and $\mathrm{FVC}, \mathrm{MVV}_{15}$, lung volumes, and maximal static pressures. Features of the maximal flow-volume loop suggestive of upper airway dysfunction were observed in 12 patients (group A), of which seven showed signs of upper airway flow limitation and five had at least three gross oscillations of flow (figure). The remaining 15 patients (group B) showed no abnormalities of upper airway function on flow-volume criteria. Four had normal curves and 11 showed a reduction of flow throughout the maximal flow-volume loop which was concave over the volume axis in inspiration as well as in expiration. The overall reduction of flow volume throughout the maximal flow-volume loop was interpreted as being due to muscle weakness. Three of the four patients who initially had normal maximal flow-volume loops developed the same low flow profile as the rest of the subjects in group B later in the course of the disease. The remaining patient was lost to follow up. In general, the pulmonary function

Table 1 Mean (SD) pulmonary function data of patients at their first visit

\begin{tabular}{|c|c|c|c|c|c|c|c|c|c|}
\hline & \multicolumn{4}{|c|}{ Group $A(n=12)$} & \multicolumn{4}{|c|}{ Group $B(n=15)$} & \multirow[b]{2}{*}{$\begin{array}{l}p \text { value } \\
A \cup B\end{array}$} \\
\hline & Overall & $\begin{array}{l}\text { Flow } \\
\text { limitation (FL) } \\
(n=7)\end{array}$ & $\begin{array}{l}\text { Oscillations (OS) } \\
(n=5)\end{array}$ & $\begin{array}{l}\text { pvalue } \\
\text { FL } v \text { OS }\end{array}$ & Overall & $\begin{array}{l}\text { Normal }(N) \\
(n=4)\end{array}$ & $\begin{array}{l}\text { Weakness (W) } \\
(n=11)\end{array}$ & $\begin{array}{l}p \text { value } \\
N v W\end{array}$ & \\
\hline $\begin{array}{l}\text { FVC (\% pred) } \\
\text { FEV (\% pred) } \\
\text { FIF } 1 \text { (1/s) } \\
\text { MVV (\% pred) } \\
\text { TLC (\% pred) } \\
\text { FRC (\% pred) } \\
\text { RV (\% pred) } \\
\text { RV/TLC\% } \\
\text { PImax (\% pred) } \\
\text { PEmax (\% pred) }\end{array}$ & $\begin{array}{r}71(19) \\
72(20) \\
116(50) \\
51(15) \\
80(9) \\
88(10) \\
102(25) \\
42(17) \\
41(17) \\
43(15)\end{array}$ & $\begin{array}{l}81(9) \\
83(10) \\
96(51) \\
48(12) \\
82(4) \\
89(9) \\
88(8) \\
39(5) \\
45(16) \\
47(13)\end{array}$ & $\begin{array}{r}57(21) \\
56(20) \\
145(32) \\
54(20) \\
78(14) \\
87(12) \\
122(28) \\
56(15) \\
36(18) \\
37(18)\end{array}$ & $\begin{array}{l}\text { NS } \\
<0 \cdot 05 \\
<0 \cdot 05 \\
\text { NS } \\
\text { NS } \\
\text { NS } \\
<0 \cdot 05 \\
<0 \cdot 05 \\
\text { NS } \\
\text { NS }\end{array}$ & $\begin{array}{r}82(27) \\
85(25) \\
222(96) \\
69(23) \\
87(15) \\
90(14) \\
97(16) \\
40(12) \\
66(23) \\
53(24)\end{array}$ & $\begin{array}{r}111(14) \\
110(18) \\
268(81) \\
94(14) \\
103(4) \\
100(11) \\
89(22) \\
30(11) \\
61(18) \\
82(9)\end{array}$ & $\begin{aligned} 71 & (22) \\
76 & (21) \\
206 & (100) \\
60 & (18) \\
81 & (14) \\
86 & (13) \\
100 & (14) \\
44 & (10) \\
68 & (27) \\
41 & (16)\end{aligned}$ & $\begin{array}{l}<0 \cdot 01 \\
<0 \cdot 01 \\
\text { NS } \\
<0.01 \\
<0 \cdot 01 \\
\text { NS } \\
\text { NS } \\
\text { NS } \\
\text { NS } \\
<0 \cdot 01\end{array}$ & $\begin{array}{l}\text { NS } \\
\text { NS } \\
<0 \cdot 01 \\
<0 \cdot 05 \\
\text { NS } \\
\text { NS } \\
\text { NS } \\
\text { NS } \\
<0 \cdot 01 \\
\text { NS }\end{array}$ \\
\hline
\end{tabular}

$\overline{F V C}=$ forced vital capacity; $\mathrm{FEV}_{1}=$ forced expiratory volume in one second; $\mathrm{FIF}_{50}=$ maximum mid inspiratory flow; $\mathrm{MVV}=$ maximal voluntary ventilation; $\mathrm{TLC}=$ total lung capacity; FRC = functional residual capacity; RV = residual volume; PImax, PEmax = maximal inspiratory and expiratory respiratory pressures; NS = not significant. 

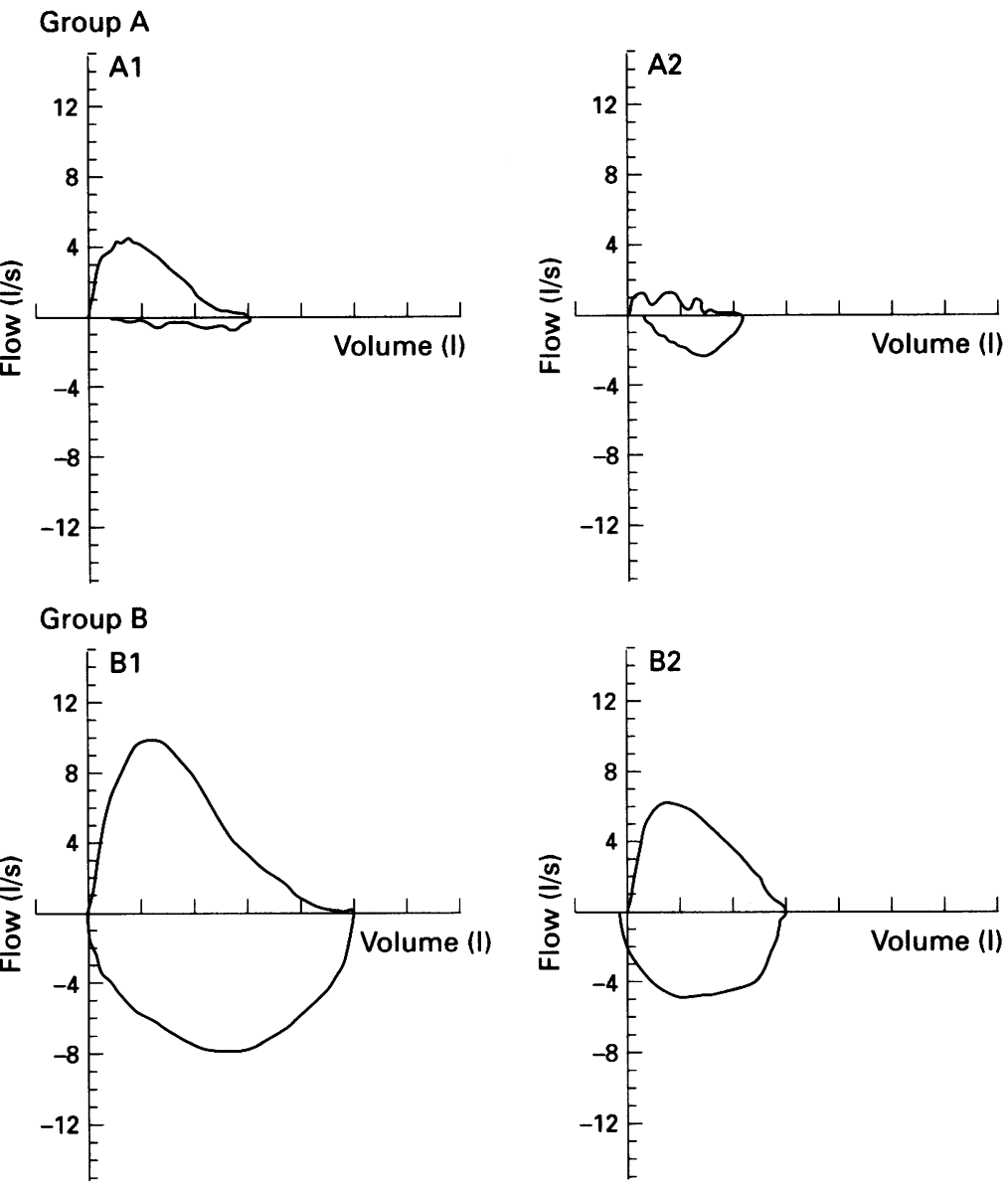

Flow-volume loop in four representative patients. Group $A$, with upper airway dysfunction: $A 1$, upper airway flow limitation; $A 2$, gross flow oscillations. Group $B$, without upper airway dysfunction: B1, normal flow-volume loop; B2, general reduction of maximal flow-volume loop.

values in group A were lower than in group $\mathrm{B}$, with those indices most related to muscle strength (MVV and Pmax) showing significant differences (table 1). As expected, the correlation between FIF $_{50}$ and PImax $(r=0.62)$ was statistically significant.

\section{MAXIMAL FLOW-VOLUME LOOP AND CLINICAL FEATURES}

Of the patients with a normal maximal flowvolume loop only one had pseudobulbar manifestations with no bulbar signs. Eleven patients in group $A$ and seven in group $B$ exhibited clinical manifestations of bulbar or pseudobulbar involvement at presentation, with Appel bulbar scores of $9 \cdot 6(2)$ and $8 \cdot 1$ (2), respectively (NS). One patient had maximal flow-volume loop signs of upper airway dysfunction and no bulbar manifestations in her first visit, but presented unequivocal bulbar symptoms at the second and subsequent visits. All six patients whose motor neurone disease started with bulbar manifestations had abnormalities suggestive of upper airway dysfunction on their maximal flow-volume loop. The presence or absence of bulbar signs at presentation was related to presence or absence of upper airway dysfunction and resulted in a $61 \%$ sensitivity and $89 \%$ specificity of the maximal flowvolume loop for the detection of bulbar involvement. Regarding the variability of the maximal flow-volume loop findings, it is worth stressing that, in the last evaluation before death, the maximal flow-volume loop generally retained the initial pattern, although weaker, and no patient needed to be reclassified because of changes in the maximal flow-volume loop.

The mean rate of progression was $4 \cdot 44$, with a range of 0.66 to 18.61 . Mean values for groups A and B of overall Appel scores, rate of progression, and time elapsed from the onset of symptoms to the first visit are shown in table 2. The differences observed between the two groups were not significant. The Appel score of the last visit before death was similar for both groups $(A=121$ (27), $B=116$ (27), NS), as was the time elapsed between the last measurement and death $(\mathrm{A}=110$ (84) days, $\mathrm{B}=95$ (69) days).

Twenty four deaths, all related to motor neurone disease, were recorded during the study (12 in each group), with no difference in duration of disease in these patients. Of the remaining three patients two were known to be alive at the end of the study.

\section{Discussion}

Few studies have evaluated the characteristics of the maximal flow-volume loop in patients with motor neurone disease. Kreitzer et $a l^{17}$ described two types of maximal flow-volume loop in 27 patients: one completely normal and the other with reduction of PEF and concavity towards the volume axis. Fallat et al ${ }^{1}$ mentioned

Table 2 Mean (SD) clinical data of patients in groups $A$ and $B$

\begin{tabular}{|c|c|c|c|c|c|c|c|c|c|}
\hline & \multicolumn{4}{|c|}{ Group $A(n=12)$} & \multicolumn{4}{|c|}{ Group $B(n=15)$} & \multirow[b]{2}{*}{$\begin{array}{l}p \text { value } \\
A v B\end{array}$} \\
\hline & Overall & $\begin{array}{l}\text { Flow } \\
\text { limitation }(F L) \\
(n=7)\end{array}$ & $\begin{array}{l}\text { Oscillations (OS) } \\
(n=5)\end{array}$ & $\begin{array}{l}\text { p value } \\
F L v O S\end{array}$ & Overall & $\begin{array}{l}\text { Normal }(N) \\
(n=4)\end{array}$ & $\begin{array}{l}\text { Weakness (W) } \\
(n=11)\end{array}$ & $\begin{array}{l}p \text { value } \\
N v W\end{array}$ & \\
\hline $\begin{array}{l}\text { Appel bulbar } \\
\text { score* }\end{array}$ & $9.6(1.9)$ & $9 \cdot 5(2 \cdot 3)$ & $9.7(1.5)$ & NS & $8 \cdot 1(2 \cdot 3)$ & $9 \cdot 0(0)$ & $8 \cdot 0(2 \cdot 4)$ & NS & NS \\
\hline $\begin{array}{l}\text { Appel total score } \\
\text { Disease } \\
\text { progression** }\end{array}$ & $\begin{array}{l}67(22) \\
5 \cdot 9(5 \cdot 3)\end{array}$ & $\begin{array}{l}59(17) \\
7 \cdot 6(6 \cdot 7)\end{array}$ & $\begin{array}{l}81(25) \\
3 \cdot 7(2 \cdot 0)\end{array}$ & $\begin{array}{l}\text { NS } \\
\text { NS }\end{array}$ & $\begin{array}{l}82(29) \\
5 \cdot 3(4 \cdot 8)\end{array}$ & $\begin{array}{l}52(10) \\
3 \cdot 8(3 \cdot 6)\end{array}$ & $\begin{array}{l}91(27) \\
5 \cdot 8(5 \cdot 1)\end{array}$ & $\begin{array}{l}<0 \cdot 05 \\
\text { NS }\end{array}$ & $\begin{array}{l}\text { NS } \\
\text { NS }\end{array}$ \\
\hline $\begin{array}{l}\text { Months elapsed } \\
\text { between first } \\
\text { manifestation and } \\
\text { first visit }\end{array}$ & $16(16)$ & $12(8)$ & $21(24)$ & NS & $22(21)$ & $25(31)$ & $22(19)$ & NS & NS \\
\hline $\begin{array}{l}\text { Months from first } \\
\text { visit to death }\end{array}$ & $\begin{array}{l}12(5) \\
(n=12)\end{array}$ & $\begin{array}{l}12(5) \\
(\mathrm{n}=7)\end{array}$ & $\begin{array}{l}12(6) \\
(n=5)\end{array}$ & NS & $\begin{array}{l}11(9) \\
(n=12)\end{array}$ & $\begin{array}{l}19(15) \\
(\mathrm{n}=2)\end{array}$ & $\begin{array}{l}10(7) \\
(n=10)\end{array}$ & NS & NS \\
\hline $\begin{array}{l}\text { Total duration of } \\
\text { disease (months) }\end{array}$ & $28(18)$ & $25(10)$ & $34(26)$ & NS & $29(22)$ & $25(16)$ & $29(24)$ & NS & NS \\
\hline
\end{tabular}

* Only patients with bulbar involvement.

** For definition see Methods section. 
flow oscillations and depicted some expiratory flow-volume curves with characteristics of airway obstruction. They observed sudden interruption of expiratory flow in patients who also had signs of bulbar involvement. ${ }^{1}$ Brach $^{18}$ presented three patients with abnormalities of the maximal flow-volume loop and called attention to the concurrence of such abnormalities with bulbar and pseudobulbar involvement, independent of, or associated with, respiratory muscle weakness, and concluded that the maximal flow-volume loop abnormalities may help to select patients for tracheostomy to prevent aspiration.

Assessment of abnormalities of the maximal flow-volume loop at presentation and their prognostic value were the main objective of our study. Five of the 12 patients with maximal flow-volume loop abnormalities showed reproducible oscillations of flow during expiration or inspiration. These may be caused by functional instability of the upper airway ${ }^{12}$ due to lack of support, or to muscle incoordination causing mechanical derangement of its wall. ${ }^{5}$ In other studies patients with flow oscillations on the maximal flow-volume loop who underwent endoscopy exhibited rapid, intermittent changes of upper airway diameter. ${ }^{19}$ In our study the remaining seven patients with maximal flow-volume loop abnormalities had flow indices consistent with upper airway flow limitation, which might be related to paresis or paralysis of the vocal cords. ${ }^{2021}$ Progress and duration of the disease was similar in patients with flow oscillations and those with flow limitation. Nakano et $a^{21}$ observed an increase of residual volume (RV) and RV/TLC in their patients with amyotrophic lateral sclerosis and attributed this to diaphragmatic weakness. In our study such an increase was present only in patients with gross oscillations in the maximal flow-volume loop, but diaphragmatic function was not evaluated. In those with features of upper airway flow limitation the possibility that these abnormalities were due to muscle weakness mimicking an obstructive patten cannot be excluded. PImax was significantly smaller in patients in group A than group B, but differences between patients with maximal flowvolume loops of flow limitation and those with oscillations were not significant.

The maximal flow-volume loop in the remaining 15 patients (group B) was normal or generally reduced, with concavity of the flow loop with respect to the volume axis. This type of curve has been attributed to generalised muscle weakness in these patients. ${ }^{22}$ Presence of this pattern may identify those patients susceptible to developing respiratory failure. ${ }^{22}$ The patients in our series with generally reduced maximal flow-volume loop did present with worse functional derangement than those with normal maximal flow-volume loop and were no more severely affected than patients with upper airway abnormalities. Deaths were fewer among patients with normal maximal flowvolume loops than for those with maximal flowvolume loops indicating muscle weakness. The differences in progress and disease duration were not significant, but the lack of significance may be related to the small number of patients included in each group. It is still possible that patients with motor neurone disease presenting with normal maximal flow-volume loop at the time of diagnosis may represent a subgroup with a better prognosis. It seems clear, however, that signs of upper airway dysfunction carry no penalty in terms of survival with respect to abnormalities denoting muscle weakness.

Among the pulmonary function tests used in this study maximal static respiratory pressures and MVV are the most sensitive indices of respiratory muscle weakness. ${ }^{23}$ The only abnormal finding in our patients with a normal maximal flow-volume loop was a low PImax. This stresses the value of recording PImax for screening purposes in patients with neuromuscular disease, especially in those with normal flows and volumes.

The possible prognostic value of abnormalities of the maximal flow-volume loop in patients with neuromuscular disease with bulbar involvement has been stressed by Vincken et al. ${ }^{2}$ At the time of the pulmonary function tests, bulbar manifestations were present in 11 of the 12 patients with upper airway dysfunction, in six of the 15 revealing no upper airway dysfunction, and in one of the patients with a normal maximal flow-volume loop. The intensity of bulbar manifestations did not vary from one subgroup to another. We suggest that, although upper airway dysfunction is seen more frequently in patients with bulbar abnormalities, it does not always accompany the latter. There was no correlation between prognosis or duration of the disease and the presence or absence of upper airway dysfunction.

In summary, upper airway dysfunction is a frequent finding in patients with motor neurone disease ( $44 \%$ of our subjects) and tends to occur more often in patients with bulbar manifestations. However, the observation of upper airway dysfunction did not by itself indicate a poorer prognosis.

1 Fallat RJ, Jewitt B, Bass M, Kamm B, Norris FH. Spirometry in amyotrophic lateral sclerosis. Arch Neurol 1979;36:7480

2 Vincken W, Elleker G, Cosio MG. Detection of upper airway muscle involvement in neuromuscular disorders using the flow-volume loop. Chest 1986;90:52-7.

3 Rotman HH, Liss HP, Weg JG. Diagnosis of upper airway obstruction by pulmonary function testing. Chest 1975 ; 68:796-9.

4 Owens GR, Murphy DMF. Spirometric diagnosis of upper airway obstruction. Arch Intern Med 1983;143:1331-4.

5 Vincken WG, Cosio MG. Flow oscillations on the flowvolume loop: clinical and physiological implications. Eur volume loop: clinical and

6 Rosen AD. Amyotrophic lateral sclerosis. Clinical features and prognosis. Arch Neurol 1978;35:638-42.

7 Quanjer PhH. Standardized lung function testing. Report of Working Party on standardization of lung function tests. European Community Coal and Steel, Luxembourg. Bull Eur Physiopathol Respir 1983;19(Suppl 5).

8 Black LF, Hyatt R. Maximal respiratory pressures: normal values and relationship to age and sex. Am Rev Respir Dis 1969;99:696-702.

9 Roca J, Sanchis J, Agusti A, et al. Spirometric reference values for a Mediterranean population. Bull Eur Physiopathol Respir 1986;22:217-24.

10 Cotes JE. Lung function. Assessment and application in medicine. 4th edn. Oxford: Blackwell, 1979:314-87.

11 Miller RD, Hyatt RE. Evaluation of obstructing lesion of the trachea and larynx by flow-volume loops. Am Rev the trachea and larynx by flow
Respir Dis 1973;108:475-82.

12 Vincken W, Cosio MG. Flow oscillations of the flow-volume loop: a nonspecific indicator of upper airway dysfunction. Bull Eur Physiopathol Respir 1985;21:559-67.

13 Empey DW. Assessment of upper airway obstruction. BMF

14 Jordanoglou J, Pride NB. A comparison of maximum in- 
spiratory and expiratory flow in health and in lung disease. Thorax 1968;23:38-45.

15 Engstrom H, Grimby G, Soderholm B. Dynamic spirometry in patients with tracheal stenosis. Acta Med Scand 1964 176:329-34

16 Appel V, Stewart SS, Smith G, Appel SH. A rating scale for amyotrophic lateral sclerosis: description and preliminary experience. Ann Neurol 1987;22:328-33.

17 Kreitzer SM, Saunders NA, Tyler HR, Ingram RH. Respiratory muscle function in amyotrophic lateral sclerosis. piratory muscle function in amyotroph

18 Brach BB. Expiratory flow patterns in amyotrophic lateral sclerosis. Chest $1979 ; 75: 648-50$.

19 Haponik EF, Munster AM, Wise RA, Smith PL, Meyers DA, Britt EJ, et al. Upper airway function in burn patients.
Correlation of flow-volume curves and nasopharyngoscopy. Am Rev Respir Dis 1984;129:251-7.

20 Cormier Y, Kashima H, Summer W, Menkes H. Upper airways obstruction with bilateral vocal cord paralysis. Chest 1979;75:423-7.

21 Nakano KK, Bass H, Tyler HR, Carmel RJ. Amyotrophic lateral sclerosis: a study of pulmonary function. Dis Ner Syst 1976;37:32-5.

22 Gupta RG. Respiratory dysfunction in motor neuron disease. In: Weiner WJ, ed. Respiratory dvsfunction in neurologic disease New York: Futura 1980:71-81.

23 Serisier DE, Mastaglia FL, Gibson GJ. Respiratory muscle function and ventilatory control. I. In patients with motor neurone disease. II. In patients with myotonic dystrophy. Qf Med 1982;202:205-26. 